\title{
Assessment of syndromic management of curable sexually transmitted and reproductive tract infections among pregnant women: an observational cross- sectional study
}

Enesia Banda Chaponda ${ }^{1 *}$ (D) Jane Bruce ${ }^{2}$, Charles Michelo ${ }^{3,4}$, Daniel Chandramohan ${ }^{2}$ and R. Matthew Chico ${ }^{2}$

\begin{abstract}
Background: This study estimated the prevalence of curable sexually transmitted and reproductive tract infections (STIS/RTIs) among pregnant women attending antenatal care (ANC) in rural Zambia, evaluated the effectiveness of syndromic management of STIS/RTIs versus reference-standard laboratory diagnoses, and identified determinants of curable STIs/RTIs during pregnancy.

Methods: A total of 1086 pregnant women were enrolled at ANC booking, socio-demographic information and biological samples were collected, and the provision of syndromic management based care was documented. The Piot-Fransen model was used to evaluate the effectiveness of syndromic management versus etiological testing, and univariate and multivariate logistic regression analyses were used to identify determinants of STIS/RTIs.
\end{abstract}

Results: Participants had a mean age of 25.6 years and a mean gestational age of 22.0 weeks. Of 1084 women, 700 had at least one STI/RTI (64.6\%; 95\% confidence interval [CI], 61.7, 67.4). Only 10.2\% of infected women received any treatment for a curable STI/RTI (excluding syphilis). Treatment was given to 0 of 56 women with chlamydia (prevalence 5.2\%; 95\% Cl, 4.0,6.6), 14.7\% of participants with gonorrhoea (prevalence 3.1\%; $95 \% \mathrm{Cl}, 2.2,4.4$ ), $7.8 \%$ of trichomoniasis positives (prevalence $24.8 \% ; 95 \% \mathrm{Cl}, 22.3,27.5$ ) and $7.5 \%$ of women with bacterial vaginosis (prevalence 48.7\%; 95\% Cl, 45.2, 51.2). An estimated 7.1\% (95\% Cl, 5.6, 8.7) of participants had syphilis and received treatment. Women < 20 years old were more likely (adjusted odds ratio $[\mathrm{aOR}]=5.01 ; 95 \% \mathrm{Cl}: 1.23,19.44$ ) to have gonorrhoea compared to women $\geq 30$. The odds of trichomoniasis infection were highest among primigravidae $(\mathrm{aOR}=2.40 ; 95 \% \mathrm{Cl}: 1.69,3.40)$, decreasing with each subsequent pregnancy. Women 20 to 29 years old were more likely to be diagnosed with bacterial vaginosis compared to women $\geq 30$ ( $\mathrm{aOR}=1.58 ; 95 \% \mathrm{Cl}: 1.19,2.10)$. Women aged 20 to 29 and $\geq 30$ years had higher odds of infection with syphilis, aOR $=3.96 ; 95 \% \mathrm{Cl}: 1.40,11.20$ and aOR $=$ 3.29; 95\% Cl: 1.11, 9.74 respectively, compared to women under 20.

* Correspondence: enesia.chaponda@gmail.com

'Department of Biological Sciences, University of Zambia, Lusaka, Zambia

Full list of author information is available at the end of the article

(c) The Author(s). 2021 Open Access This article is licensed under a Creative Commons Attribution 4.0 International License, which permits use, sharing, adaptation, distribution and reproduction in any medium or format, as long as you give appropriate credit to the original author(s) and the source, provide a link to the Creative Commons licence, and indicate if changes were made. The images or other third party material in this article are included in the article's Creative Commons licence, unless indicated otherwise in a credit line to the material. If material is not included in the article's Creative Commons licence and your intended use is not permitted by statutory regulation or exceeds the permitted use, you will need to obtain permission directly from the copyright holder. To view a copy of this licence, visit http://creativecommons.org/licenses/by/4.0/ The Creative Commons Public Domain Dedication waiver (http://creativecommons.org/publicdomain/zero/1.0/) applies to the data made available in this article, unless otherwise stated in a credit line to the data. 
(Continued from previous page)

Conclusions: Curable STIS/RTIs were common and the majority of cases were undetected and untreated.

Alternative approaches are urgently needed in the ANC setting in rural Zambia.

Keywords: Syndromic management, Sexually transmitted infections, Reproductive tract infections, Bacterial vaginosis, Prevalence, Risk factors, Sub-Saharan Africa

\section{Background}

Curable sexually transmitted and reproductive tract infections (STIs/RTIs) - chlamydia, gonorrhoea, trichomoniasis, bacterial vaginosis, and syphilis - are important causes of adverse pregnancy outcomes. Chlamydia (Chlamydia trachomatis) increases the odds of preterm birth four-fold [1], and more than doubles the chances of experiencing premature rupture of the membranes [1], delivering a newborn who is low birthweight [1] or small-forgestational age [2]. Gonorrhoea (Neisseria gonorrhoeae) is associated with a three-fold increase in preterm birth [3]. Trichomoniasis (Trichomonas vaginalis), the most prevalent curable STI in the world, increases the odds of preterm delivery 1.5 times [4]. Bacterial vaginosis, the most common urogenital disorder in the world among women of reproductive age, increases the odds of preterm delivery two-fold [4]. Bacterial vaginosis and trichomoniasis both double the odds of delivering a low birthweight child [4]. Syphilis (Treponema pallidum) is associated with four of every ten spontaneous abortions [5, 6], and one-quarter of stillbirths [7]. Pregnant women who have curable STIs are at elevated risk of HIV acquisition during pregnancy [8, 9], whereas HIV-infected pregnant women who have curable STIs at delivery are at increased risk of giving birth to an HIV-infected infant [10].

To reduce the burden of congenital syphilis, the World Health Organization (WHO) recommends universal screening of pregnant women at antenatal care (ANC) booking and the provision of 2.4MU benzathine penicillin $\mathrm{G}$ to individuals who test positive. For the diagnosis of urethral discharge and genital ulcer disease that include chlamydia, gonorrhoea, trichomoniasis, and bacterial vaginosis, the $\mathrm{WHO}$ recommends the use of diagnostic and treatment algorithms called syndromic case management [11] in low-resource areas where laboratory facilities and trained staff are unavailable. Syndromic management is based on the identification of consistent groups of symptoms and easily recognized signs and treatment that is effective against the majority or most serious organisms responsible for producing a syndrome. This approach can be effective for diagnosing and treating men. However, curable STIs/RTIs are often asymptomatic among women for whom the algorithms fail to diagnose 70 to $80 \%$ of chlamydial and gonococcal infections [12], and 60 to $70 \%$ of trichomoniasis and bacterial vaginosis cases $[13,14]$.
The co-infection prevalence estimates of STI/RTI and malaria infection among pregnant women in the Nchelenge District of Zambia has been previously reported [15]. Nchelenge is a rural area with a population of approximately 173,680 [16] on the shores of Lake Mweru in the Luapula Province. In this analysis the prevalence of curable STIs/RTIs among pregnant women, effectiveness of the syndromic case management for diagnosis of curable STIs/ RTIs compared to reference-standard laboratory assays, and risk factors for having a curable STI/RTI during pregnancy are presented.

\section{Methods}

The main study involved an observational cohort of women enrolled at first ANC visit and followed to delivery. Participants were enrolled $(n=1086)$ who were less than 32 gestational weeks measured by ultra-sound during their first ANC visit to Nchelenge and Kashikishi health facilities from November 2013 to April 2014 [17].

Consistent with Zambian ANC policy, clinic staff screened pregnant women and their partners for HIV $[18,19]$. Venous blood was collected from women for syphilis testing by rapid plasma reagin (RPR) (Omega Diagnostics Limited, Alva, Scotland, United Kingdom) and RPR-positive women were treated with $2.4 \mathrm{MU}$ of benzathine penicillin $G$ together with their partners according to national norms [20]. Clinic staff recorded participant socio-demographic information and obstetric history during the first visit. As part of standard ANC, clinic staff asked women at antenatal care visits if they had experienced any symptoms associated with STIs/ RTIs prior to enrolment. If women responded in the affirmative, they were screened further and treated based on syndromic management guidelines by the clinic staff. Apart from routine care, clinic staff collected cervicovaginal swabs and stored them at the district hospital. Samples were transported to the University Teaching Hospital in Lusaka where molecular detection of the presence of each organism of interest, $C$. trachomatis, $N$. gonorrhoeae and T. vaginalis was conducted. Polymerase chain reaction methods were used to identify species of interest with positive and negative controls at the stages of extraction, amplification and electrophoresis [21-23]. Bacterial vaginosis was diagnosed by microscopy using gold standard Nugent criteria [24]. Results of these assays were communicated to participating clinics and 
study staff who traced positive cases to their homes and encouraged women to seek treatment from the clinics at no cost. Separately, to confirm syphilis positivity, Treponema pallidum haemagglutination assays were performed (Chronolab Systems, Barcelona, Spain) on samples that were RPR seropositive.

\section{Data processing and analysis}

Data were double-entered and cleaned in EpiData software version 3.1 [25] and analysed with Stata IC 13 software [26]. The prevalence of curable STIs/RTIs and 95\% CIs were estimated, and the Piot-Fransen model was applied to evaluate the effectiveness of syndromic case management versus etiological testing in the ANC setting. The Piot-Fransen model has been previously used to identify weaknesses in case management of STIs [27], malaria [28], and tuberculosis [29]. The prevalence estimates were stratified by HIV status and odds ratios (OR) were estimated in univariate logistic regression models that contained variables we considered a priori to be potential risk factors. For each infection, risk factors were then assessed in a multivariable model using a likelihood-ratio test. Risk factors that were assessed included maternal age, gravidity, marital status, years of schooling, number of life-time sexual partners, self-reported STI/RTI related symptoms and HIV status. The final model for each infection included risk factors that demonstrated an effect in the adjusted model at the 5\% significance level and on the adjusted OR estimates for individual STIs/RTIs. Models were also produced for having any STI/RTI.

\section{Results}

In total, 1086 women were recruited to the study, with one withdrawing consent during the study. Background characteristics of participants have been reported elsewhere [15]. Briefly, women had a mean age of 25.6 years (95\% CI: 25.1, 25.9) and a mean gestational age of 22.0 weeks (95\% CI: 21.7, 22.2); 55.3\% (600 of 1085) had some primary school education, and $80.6 \%$ (874 of 1085) were married. The mean age of sexual debut was 17.2 years (range 10 to 28 years). Overall, $13.2 \%$ (95\% CI: 11.3, 15.3) of women tested positive for HIV. Multigravidae (99 of 658) had the highest prevalence of HIV, $15.0 \%$ (95\% CI: 12.5, 18.0), followed by secundigravidae (23 of 165$)$ at $13.9 \%$ (95\% CI: 9.4, 20.1\%), and 8.0\% (95\% CI: $5.3,12.0 \%)$ among primigravidae (21 of 261), Pvalue $=0.018$.

\section{Prevalence of individual STIs/RTIs}

In total, samples from 1084 women were available for analysis. However, three samples for bacterial vaginosis and seven samples for syphilis were not evaluable. Table 1 contains a complete summary of prevalence estimates of STIs/RTIs for all women and those who were
HIV positive. Among women tested, $64.6 \%$ (95\% CI, $61.7,67.4)$ had at least one curable STI/RTI (700 of 1084). An estimated 5.2\% (95\% CI: 3.9, 6.7) of participants had chlamydia (56 of 1084) with no significant difference between women with HIV and those without. Among the five curable STIs/RTIs investigated, gonorrhoea was the least prevalent (34 of 1084) at 3.1\% (95\% CI: 2.2, 4.4). Gonorrhoea was more common among HIV-infected women compared to those without HIV. One-quarter of women (269 of 1084) had trichomoniasis, $24.8 \%$ (95\% CI: $22.3,27.5)$, and there was no difference in the prevalence between HIV-infected and HIVuninfected women. Bacterial vaginosis was diagnosed among 48.2\% (95\% CI: 45.2, 51.2) of women (521 of 1081). Participants with HIV were more likely to have bacterial vaginosis, than HIV-uninfected women. An estimated 7.1\% (95\% CI: 5.6, 8.7) of participants had syphilis (76 of 1077) and the proportion was more than double among women with HIV.

\section{Effectiveness of syndromic case management}

Overall, $12.4 \%$ of women self-reported symptoms associated with STIs/RTIs at the time of recruitment and $18.0 \%$ reported experiencing symptoms during the pregnancy duration including at recruitment. Of women who had at least one curable STI/RTI, 86.0\%, (602 of 700) were asymptomatic at recruitment. Among women with chlamydia, $83.9 \%$ (47 of 56 ) were asymptomatic, as were $76.5 \%$ (26 of 34) of gonorrhoea cases, $84.4 \%$ (227 of 269 ) of trichomoniasis cases, and $86.0 \%$ (448 of 521) of women diagnosed with bacterial vaginosis. Figure 1 illustrates the Piot-Fransen model and quantifies the number as well as proportion of women tested for each STI/RTI, the proportion of symptomatic versus asymptomatic infections identified, and the number of women with STIs/ RTIs who received treatment. Overall, only 10.2\% (69 of 680) of curable STI/RTI cases, excluding syphilis, received treatment. Of the 98 symptomatic women, 43 cases were given treatment. Not one chlamydial infection of 56 was treated. In contrast, treatment was provided to $14.7 \%$ of women with gonococcal infections (5 of 34 ), $7.8 \%$ of trichomoniasis cases (21 of 269), and $7.5 \%$ of women with bacterial vaginosis (39 of 521).

The proportion of women experiencing symptomatic STIs/RTIs at recruitment was higher among HIV-positive women, 19.6\%, (28 of 143) compared to HIV-negative women, $11.3 \%$, (106 of 941), $P$-value $=0.005$. More HIVpositive participants received treatment than HIVnegative women, but this was not statistically significant, $16.4 \%$ versus $10.5 \%$, respectively, $P$-value $=0.076$.

\section{Risk factors for STIs/RTIs}

Among the five curable STIs/RTIs, only chlamydia had no particular risk factor that was identified to be 
Table 1 Prevalence of curable STIs/RTIs among all pregnant women ( $N=1084)$ at antenatal care booking and by HIV status

\begin{tabular}{|c|c|c|c|c|c|}
\hline \multirow[t]{2}{*}{ Curable STI/RTI (n) } & \multicolumn{2}{|c|}{ Cases among all women } & \multicolumn{3}{|c|}{ Cases among HIV-infected women* } \\
\hline & $\%$ positive & $95 \% \mathrm{Cl}$ & $\%$ positive & $95 \% \mathrm{Cl}$ & $P$-value \\
\hline \multicolumn{6}{|l|}{ Chlamydia } \\
\hline Positive & $56(5.2)$ & $3.9,6.7$ & $10(7.0)$ & $3.8,12.6$ & 0.291 \\
\hline Paucigravidae (426) & $28(6.6)$ & $4.6,9.4$ & $5(11.4)$ & $4.7,24.5$ & 0.236 \\
\hline Multigravidae (658) & $28(4.3)$ & $3.0,6.1$ & $5(5.1)$ & $2.1,11.7$ & 0.718 \\
\hline \multicolumn{6}{|l|}{ Gonorrhoea } \\
\hline Positive & $34(3.1)$ & $2.2,4.4$ & $9(6.3)$ & $3.3,11.7$ & 0.020 \\
\hline Paucigravidae (426 & $17(4.0)$ & $2.5,6.3$ & $3(6.8)$ & $2.2,19.5$ & 0.227 \\
\hline Multigravidae (658) & $17(2.6)$ & $1.6,4.1$ & $6(6.1)$ & $2.7,12.9$ & 0.059 \\
\hline \multicolumn{6}{|l|}{ Trichomoniasis } \\
\hline Positive & $269(24.8)$ & $22.3,27.5$ & $34(23.8)$ & $17.5,31.5$ & 0.752 \\
\hline Paucigravidae (426) & 139 (32.6) & $28.3,37.2$ & $13(29.5)$ & $17.8,44.8$ & 0.676 \\
\hline Multigravidae (658) & $130(19.8)$ & $16.9,23.0$ & $21(21.2)$ & $14.2,30.5$ & 0.745 \\
\hline \multicolumn{6}{|l|}{ Bacterial vaginosis } \\
\hline Positive & $521(48.2)$ & $45.2,51.2$ & $95(66.4)$ & $58.3,73.7$ & $<0.001$ \\
\hline Paucigravidae (423) & $212(50.1)$ & $45.4,54.9$ & $31(70.5)$ & $55.2,82.2$ & 0.001 \\
\hline Multigravidae (658) & $309(47.0)$ & $43.2,50.7$ & $64(64.6)$ & $55.6,73.5$ & 0.001 \\
\hline \multicolumn{6}{|l|}{ Syphilis } \\
\hline Positive & $76(7.1)$ & $5.6,8.7$ & $22(15.8)$ & $10.6,23.0$ & $<0.001$ \\
\hline Paucigravidae (425) & $28(6.6)$ & $4.5,9.3$ & $11(25.6)$ & $14.6,40.9$ & $<0.001$ \\
\hline Multigravidae (652) & $48(7.4)$ & $5.6,9.6$ & $11(11.5)$ & $6.4,19.7$ & 0.160 \\
\hline \multicolumn{6}{|l|}{ Any STI/RTI } \\
\hline Positive & $700(64.6)$ & $61.7,67.4$ & $110(76.9)$ & $69.2,83.2$ & 0.001 \\
\hline Paucigravidae (426) & $294(69.0)$ & $64.4,73.2$ & $38(86.4)$ & $72.5,93.8$ & 0.016 \\
\hline Multigravidae (658) & $406(61.7)$ & $57.9,65.3$ & $72(72.7)$ & $63.0,80.7$ & 0.034 \\
\hline
\end{tabular}

HIV Human Immunodeficiency Virus

Samples that were processed for the detection of each infection were as follow; detection of chlamydia, gonorrhoea and trichomoniasis 1084 samples instead of 1085 were processed; detection of syphilis 1077 instead of 1085 and for detection of bacterial vaginosis 1081 instead of 1085 samples were processed due to missing samples

The HIV status of one participant was not determined and, therefore, was excluded from this analysis

${ }^{*}$ A total of 143 participants were HIV positive, 44 paucigravidae and 99 multigravidae

¥ P-value obtained from the two-sample test of proportions which was used to test the difference in prevalence of each infection among HIV positive and HIV negative women

associated with infection. HIV infection was associated with having gonorrhoea, $(\mathrm{aOR}=2.80 ; 95 \% \mathrm{CI}: 1.25$, 6.26), adjusted for age; bacterial vaginosis $(\mathrm{aOR}=2.41$; 95\% CI: 1.66, 3.51), adjusted for age; syphilis infection $(\mathrm{aOR}=2.56 ; 95 \% \mathrm{CI}: 1.48,4.41)$ adjusted for age; the number of life-time sexual partners and having any STI/ RTI (aOR $=2.10$; 95\% CI: 1.39, 3.19), adjusted for age.

There was an inverse association between age and gonorrhoea. Compared to women 30 years and older, the odds of gonococcal infection were five-times greater among pregnant women under 20 years of age $(\mathrm{aOR}=$ 5.01; 95\% CI: 1.29,19.44), and four-times higher among participants between 20 and 29 ( $\mathrm{aOR}=4.27$; 95\% CI: 1.32, 14.94) after adjusting for HIV infection. A similar relationship between gravidity and trichomoniasis was identified. In contrast to multigravidae (4th), primigravidae had the highest odds of trichomonas infection $(\mathrm{aOR}=2.40$; $95 \%$ CI: $1.69,3.40)$, followed by secundigravidae $(\mathrm{aOR}=2.06$; 95\% CI: $1.37,3.10)$, and then multigravidae (3rd) (aOR = 1.58; 95\% CI: 1.05, 2.39) after adjusting for self-reported STI/RTI symptoms. Women 20 to 29 years of age had a $58 \%$ greater chance of experiencing bacterial vaginosis $(\mathrm{aOR}=1.58$; 95\% CI: $1.19,2.10)$ compared to women 30 years of age and older adjusted for HIV infection. Women aged below 20 years had higher odds of being diagnosed with bacterial vaginosis compared to women aged 30 years and older, but this association was not statistically significant. However, compared to women aged 30 years and above, women aged 20-29 had increased odds of infection with bacterial vaginosis, $\mathrm{aOR}=1.58$; $95 \% \mathrm{CI}: 1.19,2.10$ after adjusting for HIV status. Women younger than 20 years of age, and those between 20 to 29 years, had higher 


\begin{tabular}{|c|c|}
\hline \multicolumn{2}{|l|}{ CHLAMYDIA } \\
\hline & $1,084=$ women tested \\
\hline & $56=$ asymptomatic and symptomatic infections $(5.2 \% \text { of women })^{*}$ \\
\hline & $43=$ asymptomatic $(78.2 \%)$ \\
\hline & $12=$ symptomatic $(21.8 \%)$ \\
\hline & $0=$ women with chlamydial infections given any treatment $(0.0 \%$ of cases) \\
\hline \multicolumn{2}{|l|}{ GONORRHOEA } \\
\hline & $1,084=$ women tested \\
\hline & $34=$ asymptomatic and symptomatic infections ( $3.1 \%$ of women) \\
\hline & $24=$ asymptomatic $(70.6 \%)$ \\
\hline in & $10=$ symptomatic $(29.4 \%)$ \\
\hline ! & $5=$ women with gonococcal infections given any treatment $(14.7 \%$ of cases $) \dagger$ \\
\hline \multicolumn{2}{|l|}{ TRICHOMONIASIS } \\
\hline & $1,084=$ women tested \\
\hline & $269=$ asymptomatic and symptomatic infections ( $24.8 \%$ of women) \\
\hline & $206=$ asymptomatic $(76.6 \%)$ \\
\hline$i$ & $63=$ symptomatic $(23.4 \%)$ \\
\hline & $21=$ women with trichomonas infections given any treatment ( $7.8 \%$ of cases $) \ddagger$ \\
\hline \multicolumn{2}{|l|}{ BACTERIAL VAGINOSIS } \\
\hline & $1,081=$ women tested \\
\hline 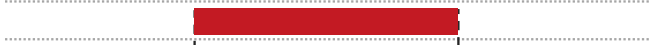 & 521 = asymptomatic and symptomatic infections ( $48.2 \%$ of women) \\
\hline 1 & $446=$ asymptomatic $(86.3 \%)$ \\
\hline 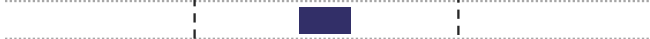 & $71=$ symptomatic $(13.7 \%)$ \\
\hline 1 & $39=$ women with bacterial vaginosis given any treatment ( $7.5 \%$ of cases) $\S$ \\
\hline \multicolumn{2}{|c|}{$\begin{array}{l}\text { *Asymptomatic versus symptomatic status was unavailable from one woman with chlamydia and bacterial vaginosis; } \$ 4 \text { were asymptomatic; } \neq 9 \text { were asymptomatic; } \$ 28 \text { were } \\
\text { asymptomatic. } \square=\text { = Number and proportion of cases of all pregnant women who could have been diagnosed and treated had etiological assays for curable STIs/RTIs been used. }\end{array}$} \\
\hline \multicolumn{2}{|c|}{$\begin{array}{l}\text { Fig. } 1 \text { Effectiveness of syndromic management of curable STIS/RTIs among pregnant women in the Nchelenge District, Zambia. * Asymptomatic } \\
\text { versus symptomatic status was unavailable from one woman with chlamydia and bacterial vaginosis; } † 4 \text { were asymptomatic; } \neq 9 \text { were } \\
\text { asymptomatic; } § 28 \text { were asymptomatic }\end{array}$} \\
\hline
\end{tabular}

odds of having any STI/RTI compared to pregnant counterparts 30 years and above, aOR $=1.70 ; 95 \% \mathrm{CI}: 1.16,2.78$ and $\mathrm{aOR}=1.58 ; 95 \% \mathrm{CI}: 1.18,2.11$, respectively, after adjusting for HIV infection.

There was a statistically significant association between syphilis and age. Compared to participants under the age of 20 , the odds of a syphilis infection were four-times higher among women from 20 to $29,(\mathrm{aOR}=3.96$; $95 \% \mathrm{CI}$ : $1.40,11.20)$, and three-times higher among women 30 and older, $(\mathrm{aOR}=3.29$; 95\% CI: 1.11, 9.74) adjusted for HIV infection and number of life-time sexual partners. The odds of having syphilis nearly doubled among women who had three or more life-time partners versus those who had just one or two partners $(\mathrm{aOR}=1.82$; 95\% CI: 1.12, 2.98) adjusted for HIV-infection and age. Table 2 shows a summary of the crude and adjusted ORs of risk factors for each STI/RTI. Supplementary Tables 1, 2, 3, 4, 5, 6 contain complete results for the risk-factor models for individual infections and composite STIs/RTIs.

\section{Discussion}

The prevalence of curable STIs among pregnant women is substantial throughout low- and middle-income countries [30]. Nearly two-thirds of all pregnant women in our cohort had a curable STI/RTI at antenatal booking. These findings are consistent with the pooled prevalence estimates of curable STIs/RTIs among pregnant women attending ANC services across East and Southern Africa [31]. The distribution of infection within this study group may have been affected by the large proportion of multigravidae, $60.7 \%$ (659 of 1085). This age structure may have made it more difficult to detect young age as a risk factor for chlamydia as reported elsewhere among pregnant [32] and non-pregnant women [33]. HIV-infected pregnant women aged less than 25 years were found to have higher odds of infection with chlamydia, gonorrhoea or trichomoniasis [34]. However, other studies have reported failure to identify any particular risk factors for chlamydial infection $[35,36]$ as in the current study. Risk factors associated with gonorrhoea were age related, i.e. being younger than age 30, similar to findings from Botswana and may suggest circulation of Neisseria gonorrhoea in younger networks of sexually active individuals [37].

Bacterial vaginosis was associated with HIV infection, a common observation among mothers with HIV [38, 39]. Syphilis prevalence was alarmingly high in our study, 7.1\% 
Table 2 Risk factors associated with gonorrhoea, trichomoniasis, syphilis, bacterial vaginosis and any sexually transmitted and reproductive tract infection among pregnant women at antenatal care booking

\begin{tabular}{|c|c|c|c|c|c|}
\hline Risk factor & $\%$ positive & $\%$ negative $^{*}$ & Women per strata & $\begin{array}{l}\text { Crude odds } \\
\text { ratio }(95 \% \mathrm{Cl})\end{array}$ & $\begin{array}{l}\text { Adjusted odds ratio } \\
(95 \% \mathrm{Cl})\end{array}$ \\
\hline \multicolumn{6}{|l|}{ Gonorrhoea } \\
\hline \multicolumn{6}{|l|}{ Age group } \\
\hline$<20$ & 3.9 & 96.1 & 204 & $4.14(1.08,15.78)$ & $5.01(1.29,19.44)$ \\
\hline $20-29$ & 4.0 & 96.0 & 573 & $4.24(1.26,14.22)$ & $4.27(1.32,14.94)$ \\
\hline $30+$ & 1.0 & 99.0 & 307 & Ref & Ref \\
\hline \multicolumn{6}{|l|}{ HIV status } \\
\hline Negative & 2.7 & 97.3 & 940 & Ref & Ref \\
\hline Positive & 6.3 & 93.7 & 143 & $2.46(1.12,5.38)$ & $2.80(1.25,6.26)$ \\
\hline \multicolumn{6}{|l|}{ Trichomoniasis } \\
\hline \multicolumn{6}{|l|}{ Pregnancy number } \\
\hline Primigravidae & 34.1 & 65.9 & 261 & $2.39(1.69,3.38)$ & $2.40(1.69,3.40)$ \\
\hline Secundigravidae & 30.3 & 69.7 & 165 & $2.01(1.34,3.02)$ & $2.06(1.37,3.10)$ \\
\hline Multigravidae (3rd) & 25.0 & 75.0 & 180 & $1.54(1.02,2.32)$ & $1.58(1.05,2.39)$ \\
\hline Multigravidae (4th) & 17.8 & 82.2 & 478 & Ref & Ref \\
\hline \multicolumn{6}{|c|}{ Self-reported STI/RTI symptoms during current pregnancy } \\
\hline No & 23.4 & 76.6 & 880 & Ref & Ref \\
\hline Yes & 31.8 & 68.2 & 198 & $1.53(1.09,2.14)$ & $1.56(1.11,2.20)$ \\
\hline \multicolumn{6}{|l|}{ Bacterial vaginosis } \\
\hline \multicolumn{6}{|l|}{ Age group } \\
\hline$<20$ & 44.6 & 55.4 & 202 & $1.10(0.76,1.57)$ & $1.23(0.85,1.77)$ \\
\hline $20-29$ & 52.7 & 47.3 & 571 & $1.53(1.15,2.02)$ & $1.58(1.19,2.10)$ \\
\hline $30+$ & 42.2 & 57.8 & 308 & Ref & Ref \\
\hline \multicolumn{6}{|l|}{ HIV status } \\
\hline Negative & 45.5 & 54.5 & 937 & Ref & NA \\
\hline Positive & 66.4 & 33.6 & 143 & $2.37(1.64,3.44)$ & $2.41(1.66,3.51)$ \\
\hline \multicolumn{6}{|l|}{ Syphilis } \\
\hline \multicolumn{6}{|l|}{ Age group } \\
\hline$<20$ & 2.0 & 98.0 & 204 & Ref & Ref \\
\hline $20-29$ & 8.6 & 91.4 & 568 & $4.72(1.68,13.25)$ & $3.96(1.40,11.20)$ \\
\hline $30+$ & 7.5 & 92.5 & 305 & $4.08(1.39,11.97)$ & $3.29(1.11,9.74)$ \\
\hline \multicolumn{6}{|c|}{ Number of lifetime sexual partners } \\
\hline$\leq 2$ & 5.7 & 94.3 & 792 & Ref & Ref \\
\hline$\geq 3$ & 11.3 & 88.7 & 275 & $2.11(1.31,3.41)$ & $1.82(1.12,2.98)$ \\
\hline \multicolumn{6}{|l|}{ HIV status } \\
\hline Negative & 5.8 & 94.2 & 938 & Ref & Ref \\
\hline Positive & 15.8 & 84.2 & 139 & $3.08(1.81,5.24)$ & $2.56(1.48,4.41)$ \\
\hline \multicolumn{6}{|l|}{ Any STI/RTI } \\
\hline \multicolumn{6}{|l|}{ Age group } \\
\hline$<20$ & 67.7 & 32.4 & 204 & $1.56(1.07,2.25)$ & $1.70(1.16,2.78)$ \\
\hline $20-29$ & 67.4 & 32.6 & 573 & $1.54(1.15,2.04)$ & $1.58(1.18,2.11)$ \\
\hline $30+$ & 57.3 & 42.6 & 307 & Ref & Ref \\
\hline
\end{tabular}


Table 2 Risk factors associated with gonorrhoea, trichomoniasis, syphilis, bacterial vaginosis and any sexually transmitted and reproductive tract infection among pregnant women at antenatal care booking (Continued)

\begin{tabular}{|c|c|c|c|c|c|}
\hline Risk factor & $\%$ positive & $\%$ negative $^{*}$ & Women per strata & $\begin{array}{l}\text { Crude odds } \\
\text { ratio }(95 \% \mathrm{Cl})\end{array}$ & $\begin{array}{l}\text { Adjusted odds ratio } \\
(95 \% \mathrm{Cl})\end{array}$ \\
\hline \multicolumn{6}{|l|}{ HIV status } \\
\hline Negative & 62.8 & 37.2 & 940 & Ref & Ref \\
\hline Positive & 76.9 & 23.3 & 143 & $1.98(1.31,2.98)$ & $2.10(1.39,3.19)$ \\
\hline
\end{tabular}

${ }^{*}$ For bacterial vaginosis the number included the intermediate and normal subgroups

*Adjusted for all the variables in the left-hand column of Supplemental Tables 1, 2, 3, 4, 5; The multivariate model only included factors that were significant at $P<0.05$ using the likelihood ratio test. Ref $=$ Reference group with the odds ratio set at 1

overall. At the population level, syphilis infection tends to be more common among older women and, therefore, having a large proportion of multigravidae in our cohort may have skewed the prevalence of maternal syphilis upward. The reason for this may be related to the natural course of the disease. After initial ulcers of primary infection heal, syphilis often becomes asymptomatic, persisting untreated for years. In our cohort study, primi- and secundigravidae represented $36.8 \%$ of syphilis infections (28 of 76 ), whereas $63.2 \%$ (48 of 76) were multigravidae. Even given the age structure of our cohort, women of Nchelenge District may experience a disproportionate burden of maternal syphilis. In 2012, an estimated $2.4 \%$ of pregnant women in Zambia had syphilis, increasing marginally to $2.5 \%$ by 2016 [40]. In sub-Saharan Africa, $1.6 \%$ of pregnant women had syphilis in 2012, lowering slightly to $1.5 \%$ in 2016 [40].

Identification of risk factors for infection can play a role in the development of a profile for high risk groups for the purpose of directing the limited resources to where they are needed most. Development of a tool to identify women at high risk of infection can allow for either provision of presumptive treatment to high risk pregnant women or screening high risk pregnant women at ANC visits for STI/RTIs and provision of treatment for positive cases.

\section{Public health response}

Syndromic management of curable STIs/RTIs clearly demonstrated limited utility given that only $10.2 \%$ of women with infections, apart from syphilis, received any treatment. Of the women with symptomatic curable STI/RTI, $43.9 \%$ received treatment according to national norms. Women were asked whether they were experiencing anything from a list of STI/RTI related symptoms. This created the basis of the classification of women to the symptomatic and asymptomatic group. However, responses to individual symptoms were not recorded. Consequently, it is not possible to draw conclusions about the appropriateness of the care that was administered.

Even under optimal circumstances, syndromic management is unlikely to perform much better given that
$86 \%$ of the curable STIs/RTIs were asymptomatic in this setting. High prevalence of untreated STIs/RTIs means high prevalence of avoidable adverse pregnancy outcomes. The shortcomings of syndromic management in pregnancy have been documented [10,32, 41], but public health responses have been lacking. Given that point of care (POC) tests for C. trachomatis, $N$. gonorrhoea and $T$. vaginalis are available [42], there is an urgent need to evaluate them in the antenatal setting as an alternative to syndromic management, particularly where risk factors may be used to guide testing [43]. Studies indicate that integration of POC diagnostic STI screening into first ANC among pregnant HIV-infected women is feasible [44, 45] and acceptable [44] although this has not been evaluated in mixed populations of HIVinfected and HIV-uninfected pregnant women. Due to lack of infrastructure and trained laboratory staff, conventional testing for STIs/RTIs is often unavailable in resource poor settings such as this study site. Until the necessary capacity is present, POC tests represent an important alternative for diagnosing chlamydia, gonorrhoea and trichomoniasis in such areas.

\section{Chlamydia and gonorrhoea}

Chlamydia and gonorrhoea POC tests merit investigation. Given that each test represents a fixed-cost, it would be useful to explore whether the use of POC tests among women who are at risk of chlamydia and gonorrhoea might be able to achieve similar reductions in adverse pregnancy outcomes attributable to these infections as universal screening and case management. In this study group, no specific risk factors for women who had chlamydial infection were identified. Consequently, universal POC testing should be considered in this setting first and foremost until a more targeted approach can be established based on risk profiles for chlamydial infection in this population. In the case of gonorrhoea, universal POC testing should be evaluated against an approach of targeted screening for pregnant women under 30 years of age, or those with HIV infection.

It would be important to establish differential diagnoses between chlamydia and gonorrhoea due of treatment implications, even though just three of 90 (3.3\%) 
pregnant women in Nchelenge were co-infected. The WHO recommends treating chlamydia during pregnancy with a one-time $1 \mathrm{~g}$ dose of azithromycin. The same dose, however, may also hasten the emergence of untreatable gonorrhoea among women with co-infection [46]. Gonorrhoea in pregnancy, per WHO guidelines, should be treated with either ceftriaxone $250 \mathrm{mg}$ by intramuscular injection plus azithromycin $1 \mathrm{~g}$ orally, or cefixime $400 \mathrm{mg}$ orally plus azithromycin $1 \mathrm{~g}$ orally [47]. If differential diagnoses cannot be established, there may be reason to provide a curative dose for gonorrhoea which would clear co-infection and reduce opportunity for gonococcus to be exposed to azithromycin monotherapy. Screening and treatment of infected partners needs to be provided with such an approach. There is a convenient dual-cassette POC test available that can detect chlamydia and gonorrhoea with one biological sample [42], but cost is significant barrier to routine use.

\section{Trichomoniasis and bacterial vaginosis}

Universal screening and treatment for trichomoniasis and bacterial vaginosis would be an important improvement over syndromic management, particularly given how prevalent both are in this setting. Pregnant women diagnosed with either trichomoniasis or bacterial vaginosis could be given a single 2-g dose of metronidazole as recommended by the WHO [48]. Another option might be simply to provide metronidazole to all women at ANC booking. These two approaches need to be evaluated for their protective effect against adverse pregnancy outcomes and the cost per adverse outcome averted. Part of the comparison should include partner screening for trichomoniasis and appropriate case management.

\section{Syphilis}

Efforts must be redoubled to ensure syphilis POC tests are available to all women at ANC booking and that 2.4 MU benzathine penicillin $G$ is in stock to treat cases. As with other curable STIs, partner screening and treatment is needed to prevent re-exposure from infected partners. In the case of syphilis, this is particularly important. Vertical transmission of syphilis has been reported in all stages and sub-stages of infection. However, congenital infection is more likely to occur and be most severe among pregnant women with first-stage syphilis (which includes primary, secondary and early-latent infections up to 2 years following exposure) than second-stage syphilis. Thus, if a woman is at risk of reinfection or resident in communities where syphilis prevalence is high, monthly quantitative titres are suggested from the third trimester to delivery [49].

This observational cross-sectional study is not without limitations. The prevalence and risk factors for curable STIs/RTIs we observed may not reflect all pregnant women in rural Zambia if there were differences between women who seek antenatal care and those who do not. Any difference, however, would not likely change the results substantially because ANC attendance (minimum one visit) in this part of Zambia was 94.6\% [50], and the refusal rate in the study among eligible women was less than $1 \%$. Another study limitation relates to the type of information required for comprehensive risk factor analyses. Some women, for example, may have been reluctant to provide accurate responses to questions related to sexual behaviour and practices. This is particularly the case given the increasing participation of male partners at the first ANC visit. In the current study, women were asked whether they were experiencing any STI/RTI symptoms. Responses, however, were not differentiated. Therefore, it was only possible to determine whether treatment was given to symptomatic women, but not if the treatment was appropriate. Another limitation is that information on alcohol or substance abuse was not collected. Finally, the study was under powered to detect risk factors with ORs $<1.5$. Regardless, results from this observational cross-sectional study clearly show that the status quo is unacceptable and that new interventions are warranted. STI vaccines remains under development. Until they are ready to deploy, clinical trials are urgently needed across a range of epidemiological settings to identify the optimal mix of interventions that is efficacious, cost-effective, and superior to the syndromic management of STIs/RTIs in pregnancy.

\section{Conclusions}

There was a high prevalence of curable STIs/RTIs in this population of pregnant women, a large proportion of which were not diagnosed and thus untreated. Syndromic management of curable STIS/RTIs is inadequate in this rural antenatal setting.

\section{Supplementary Information}

The online version contains supplementary material available at https://doi. org/10.1186/s12884-021-03573-3

\footnotetext{
Additional file 1: Supplementary Table 1. Chlamydia: Univariate and multivariate logistic regression analysis of potential risk factors of infection among pregnant women at antenatal care booking. Supplementary Table 2. Gonorrhoea: Univariate and multivariate logistic regression analysis of determinants of infection among pregnant women at antenatal care booking. Supplementary Table 3.

Trichomoniasis: Univariate and multivariate logistic regression analysis of determinants of infection among pregnant women at antenatal care booking. Supplementary Table 4. Bacterial vaginosis: Univariate and multivariate logistic regression analysis of determinants of infection among pregnant women at antenatal care booking. Supplementary Table 5. Syphilis: Univariate and multivariate logistic regression analysis of determinants of infection among pregnant women at antenatal care booking. Supplementary Table 6. Any Sexually transmitted and reproductive tract infection: Univariate and multivariate logistic regression analysis of determinants of infection among pregnant women at antenatal care booking.
} 


\section{Abbreviations}

ANC: Antenatal clinic; aOR: Adjusted Odds ratio; Cl: Confidence interval; HIV: Human immunodeficiency virus; OR: Odds ratio; RPR: Rapid plasma reagin; STI/RTI: Sexually transmitted and reproductive tract infection

\section{Acknowledgements}

We would like to thank the ANC staff at Nchelenge and Kashikishi health centres and the Nchelenge District Health Management Team.

\section{Authors' contributions}

DC and RMC contributed to the study conception and design and supervised the study. EC contributed to the conception and design of the study, conducted the field work and processed the samples, analysed data as part of her PhD work. JB and RMC assisted with the analysis plan and data analysis. CM contributed to the conception of the study, assisted with securing partial funding and supervised the study locally. All authors substantially revised manuscript and have approved the submitted version, and have agreed both to be personally accountable for these contributions and to ensure that questions related to the accuracy or integrity of any part of the work, even ones in which the author was not personally involved, are appropriately investigated, resolved, and the resolution documented in the literature.

\section{Funding}

Funding for the field work was provided by the following:

1. International Center of Excellence for Malaria Research (ICEMR) in Southern Africa, and the US National Institutes of Health for the financial support from $\mathrm{NIH/NIAID} \mathrm{grant} \mathrm{U19AI089680} \mathrm{(Malaria} \mathrm{Transmission} \mathrm{and} \mathrm{The} \mathrm{Impact} \mathrm{of}$ Control Efforts in Southern Africa) with John Hopkins University Bloomberg School of Public Health and the University of Zambia School of Medicine (UNZA-SOM).

2. The Southern African Consortium for Research Excellence (SACORE), which is part of the African Institutions Initiative grant of the Wellcome Trust (company no. 2711000), a charity (no. 210183) registered in England. 3. Tuition fees for the principle author's studentship at the London School of Hygiene and Tropical Medicine was paid by the Commonwealth Scholarship Commission in the United Kingdom.

\section{Availability of data and materials}

The datasets used and/or analysed during the current study are available from the corresponding author on reasonable request.

\section{Ethics approval and consent to participate}

The study protocol was reviewed and approved by the University of Zambia Biomedical Research Ethics Committee, reference number 004-02-13 and the London School of Hygiene and Tropical Medicine Observational/ Interventions Research Ethics Committee (reference number 6292) before the research was carried out. In addition, the Ministry of Health in Zambia also reviewed the research proposal after ethical approval had been granted. The research project was then discussed with relevant local authorities in the study district such as the District Health Management Team, community leaders and the in-charge personnel at the two health centres that were used as recruitment sites.

At the beginning of each ANC booking session an explanation of the project was given to the group of first ANC attendees and their spouses/guardians/ partners in addition to the routine weekly health talk. The information included the aims of the study, the methods of data and sample collection, number of participants required, potential advantages and disadvantages of participation and the expected benefits of carrying out the research. Potential participants were informed that participation was voluntary and participants could withdraw at any time. First ANC attendees who were willing to know more about the study were given the information sheet translated into the local language (Bemba).

There was no age cut off for exclusion because inclusion of younger pregnant women was considered to be important in order to have better representation of pregnant women. The study was performed in accordance with the Declaration of Helsinki and all included participants signed informed consent. In the case of women aged below 18 years written consent was signed by their guardians after they assented. To ensure confidentiality interviews were conducted privately and each participant was assigned a unique identity number that was used to anonymise biological samples, questionnaires, and result record forms.

\section{Consent for publication}

Not applicable.

\section{Competing interests}

The authors declare that they have no competing interests.

\section{Author details}

${ }^{1}$ Department of Biological Sciences, University of Zambia, Lusaka, Zambia. ${ }^{2}$ Department of Disease Control, Faculty of Infectious and Tropical Diseases, London School of Hygiene and Tropical Medicine, London, UK. ${ }^{3}$ Department of Epidemiology, School of Public Health, University of Zambia, Lusaka, Zambia. ${ }^{4}$ Strategic Centre for Health Systems Metrics and Evaluations, School of Public Health, University of Zambia, Lusaka, Zambia.

Received: 21 April 2020 Accepted: 19 January 2021

Published online: 30 January 2021

\section{References}

1. Gravett MG, Nelson HP, DeRouen T, Critchlow C, Eschenbach DA, Holmes KK. Independent associations of bacterial vaginosis and chlamydia trachomatis infection with adverse pregnancy outcome. J Am Med Assoc. 1986;256(14):1899-903.

2. Association of Chlamydia trachomatis and Mycoplasma hominis with intrauterine growth retardation and preterm delivery. The John Hopkins study of cervicitis and adverse pregnancy outcome. Am J Epidemiol. 1989; 129(6):1247-57.

3. Elliott B, Brunham RC, Laga M, Piot P, Ndinya-Achola JO, Maitha G, et al. Maternal gonococcal infection as a preventable risk factor for low birth weight. J Infect Dis. 1990;161(3):531-6.

4. Chico RM, Hack BB, Newport MJ, Ngulube E, Chandramohan D. On the pathway to better birth outcomes? A systematic review of azithromycin and curable sexually transmitted infections. Expert Rev Anti-Infect Ther. 2013; 11(12):1303-32.

5. Williams JW. A textbook of obstetrics. 6th ed. New York: D Appleton \& Co; 1923.

6. Ratnam AV, Din SN, Hira SK, Bhat GJ, Wacha DS, Rukmini A, et al. Syphilis in pregnant women in Zambia. Br J Vener Dis. 1982;58(6):355-8.

7. Watson-Jones D, Changalucha J, Gumodoka B, Weiss H, Rusizoka M, Ndeki L, et al. Syphilis in pregnancy in Tanzania. I. Impact of maternal syphilis on outcome of pregnancy. J Infect Dis. 2002;186(7):940-7.

8. Joseph Davey DL, Wall KM, Kilembe W, Naw HK, Brill I, Vwalika B, et al. HIV Incidence and Predictors of HIV Acquisition From an Outside Partner in Serodiscordant Couples in Lusaka, Zambia. J Acquir Immune Defic Syndr (1999). 2017;76(2):123-31.

9. Kinuthia J, Drake AL, Matemo D, Richardson BA, Zeh C, Osborn L, et al. HIV acquisition during pregnancy and postpartum is associated with genital infections and partnership characteristics. Aids. 2015;29(15):2025-33.

10. Adachi K, Klausner JD, Bristow CC, Xu J, Ank B, Morgado MG, et al. Chlamydia and gonorrhea in HIV-infected pregnant women and infant HIV transmission. Sex Transm Dis. 2015;42(10):554-65.

11. World Health Organization. Management of patients with sexually transmitted diseases. Report of a WHO Study Group, vol. 810: Geneva: World Health Organization ; 1991

12. World Health Organization. Global prevalence and incidence of selected curable sexually transmitted infection: overview and estimates. Geneva: World Health Organisation; 1991.

13. Msuya SE, Uriyo J, Stray-Pedersen B, Sam NE, Mbizvo EM. The effectiveness of a syndromic approach in managing vaginal infections among pregnant women in northern Tanzania. East Afr J Public Health. 2009;6(3):263-7.

14. Baisley K, Changalucha J, Weiss HA, Mugeye K, Everett D, Hambleton I, et al. Bacterial vaginosis in female facility workers in North-Western Tanzania: prevalence and risk factors. Sex Transm Infect. 2009;85(5):370-5.

15. Chaponda EB, Chico RM, Bruce J, Michelo C, Vwalika B, Mharakurwa S, et al. Malarial infection and curable sexually transmitted and reproductive tract infections among pregnant women in a Rural District of Zambia. Am J Trop Med Hyg. 2016;95(5):1069-76.

16. Central Statistical Office (CSO). 2010 Census of population and housing. Lusaka: Central Statistical Office; 2011. 
17. Chaponda EB, Chandramohan D, Michelo C, Mharakurwa S, Chipeta J, Chico RM. High burden of malaria infection in pregnant women in a rural district of Zambia: a cross-sectional study. Malar J. 2015;14:380.

18. Ministry of Health. Antenatal Care Guidelines for a Positive Preganancy Experience. Lusaka: Ministry of Health; 2019.

19. Ministry of Health. Zambia Consolidated guidelines for Treatment and Prevention of HIV. Lusaka: Ministry of Health; 2020.

20. Johns Hopkins Point of Care Technology Center Zambia HIV National Guidelines 2008. Available from: http://zm.one.un.org/ba/nac/hivguidelines/ guidelines/index544d.html?navigationld=429785\&siteld=429188\#429785.

21. Chaudhry U, Saluja D. Detection of Neisseria gonorrhoeae by PCR using orf1 gene as target. Sex Transm Infect. 2002;78(1):72.

22. Kengne P, Veas F, Vidal N, Rey JL, Cuny G. Trichomonas vaginalis: repeated DNA target for highly sensitive and specific polymerase chain reaction diagnosis. Cell Mol Biol (Noisy-le-Grand, France). 1994;40(6):819-31.

23. Schachter J. DFA, EIA, PCR, LCR and other technologies: what tests should be used for diagnosis of chlamydia infections? Immunol Investig. 1997;26(12):157-61.

24. Nugent RP, Krohn MA, Hillier SL. Reliability of diagnosing bacterial vaginosis is improved by a standardized method of gram stain interpretation. J Clin Microbiol. 1991;29(2):297-301.

25. Lauritsen JM, Bruus M. EpiData (version 3.1). A comprehensive tool for validated entry and documentation of data. Odense: The EpiData Association; 2003-2005.

26. StataCorp. Stata Statistical Software: Release 13. College Station: StataCorp LP; 2013.

27. Buvé A, Changalucha J, Mayaud P, Gavyole A, Mugeye K, Todd J, et al. How many patients with a sexually transmitted infection are cured by health services? A study from Mwanza region, Tanzania. Tropical Med Int Health. 2001;6(12):971-9.

28. Mumba M, Visschedijk J, Cleeff MV, Hausman B. A Piot model to analyse case management in malaria control programmes. Tropical Med Int Health. 2003;8(6):544-51.

29. Piot M. A simulation model of case finding and treatment in tuberculosis control programmes. Geneva: World Health Organization; 1967.

30. Joseph Davey DL, Shull HI, Billings JD, Wang D, Adachi K, Klausner JD. Prevalence of curable sexually transmitted infections in pregnant women in Low- and middle-income countries from 2010 to 2015: a systematic review. Sex Transm Dis. 2016;43(7):450-8.

31. Chico RM, Mayaud P, Ariti C, Mabey D, Ronsmans C, Chandramohan D. Prevalence of malaria and sexually transmitted and reproductive tract infections in pregnancy in sub-Saharan Africa: a systematic review. J Am Med Assoc. 2012;307(19):2079-86.

32. Romoren M, Sundby J, Velauthapillai M, Rahman M, Klouman E, Hjortdahl P. Chlamydia and gonorrhoea in pregnant Batswana women: time to discard the syndromic approach? BMC Infect Dis. 2007;7:27.

33. Buve A, Weiss HA, Laga M, Van Dyck E, Musonda R, Zekeng L, et al. The epidemiology of gonorrhoea, chlamydial infection and syphilis in four African cities. AIDS. 2001;15(Suppl 4):S79-88.

34. Mudau M, Peters RP, De Vos L, Olivier DH, Davey DJ, Mkwanazi ES, et al. High prevalence of asymptomatic sexually transmitted infections among human immunodeficiency virus-infected pregnant women in a low-income south African community. Int J STD AIDS. 2018;29(4):324-33.

35. Lujan J, de Onate WA, Delva W, Claeys P, Sambola F, Temmerman M, et al. Prevalence of sexually transmitted infections in women attending antenatal care in Tete province, Mozambique. South Afr Med J. 2008;98(1):49-51.

36. Menendez C, Castellsague X, Renom M, Sacarlal J, Quinto L, Lloveras B, et al. Prevalence and risk factors of sexually transmitted infections and cervical neoplasia in women from a rural area of southern Mozambique. Infect Dis Obstet Gynecol. 2010;2010:1-9. https://downloads.hindawi.com/journals/ idog/2010/609315.pdf

37. Romoren M, Sundby J, Velauthapillai M, Rahman M, Klouman E, Hjortdahl P. Chlamydia and gonorrhoea in pregnant Botswana women: time to discard the syndromic approach? BMC Infect Dis. 2007;7:27.

38. Jamieson DJ, Duerr A, Klein RS, Paramsothy P, Brown W, Cu-Uvin S, et al. Longitudinal analysis of bacterial vaginosis: findings from the HIV epidemiology research study. Obstet Gynecol. 2001;98(4):656-63.

39. Warren D, Klein RS, Sobel J, Kieke B Jr, Brown W, Schuman P, et al. A multicenter study of bacterial vaginosis in women with or at risk for human immunodeficiency virus infection. Infect Dis Obstet Gynecol. 2001;9(3):133-41.
40. Korenromp EL, Rowley J, Alonso M, Mello MB, Wijesooriya NS, Mahiane SG, et al. Global burden of maternal and congenital syphilis and associated adverse birth outcomes_estimates for 2016 and progress since 2012. PLoS One. 2019:14(2):e0211720.

41. Wangnapi RA, Soso S, Unger HW, Sawera C, Ome M, Umbers AJ, et al. Prevalence and risk factors for Chlamydia trachomatis, Neisseria gonorrhoeae and Trichomonas vaginalis infection in pregnant women in Papua New Guinea. 2015;91(3):194-200.

42. Herbst de Cortina S, Bristow CC, Joseph Davey D, Klausner JD. A Systematic Review of Point of Care Testing for Chlamydia trachomatis, Neisseria gonorrhoeae, and Trichomonas vaginalis. Infect Dis Obstet Gynecol. 2016; 2016:4386127.

43. Grant JS, Chico RM, Lee AC, Low N, Medina-Marino A, Molina RL, et al. Sexually transmitted infections in pregnancy: a narrative review of the global research gaps, challenges, and opportunities. Sex Transm Dis. 9000; Publish Ahead of Print.

44. Morikawa E, Mudau M, Olivier D, de Vos L, Joseph Davey D, Price C, et al. Acceptability and feasibility of integrating point-of-care diagnostic testing of sexually transmitted infections into a south African antenatal care program for HIV-infected pregnant women. Infect Dis Obstet Gynecol. 2018;2018: 3946862.

45. Peters RPH, de Vos L, Maduna L, Mudau M, Klausner JD, Kock MM, et al. Laboratory validation of Xpert chlamydia trachomatis/Neisseria gonorrhoeae and Trichomonas vaginalis testing as performed by nurses at three primary health care facilities in South Africa. J Clin Microbiol. 2017;55(12):3563-5.

46. Johnson AP, Hughes G. The prospect of untreatable gonorrhoea. BMJ. 2017; Publishing Group

47. World Health Organization. WHO guidelines for the treatment of Neisseria gonorrhoeae. Geneva: World Health Organization; 2016.

48. World Health Organization. STIs/RTIs: Guide to Essential Practice. Geneva: World Health Organisation; 2005.

49. Wendel GD Jr, Sheffield JS, Hollier LM, Hill JB, Ramsey PS, Sánchez PJ. Treatment of Syphilis in Pregnancy and Prevention of Congenital Syphilis. Clin Infect Dis. 2002;35(Supplement_2):S200-S9.

50. Central Statistical Office/Zambia, Ministry of Health/Zambia, University of Zambia Teaching Hospital Virology Laboratory, University of Zambia Department of Population Studies, Tropical Diseases Research Centre/ Zambia, ICF International. Zambia Demographic and Health Survey 2013-14. Rockville: Central Statistical Office/Zambia, Ministry of Health/Zambia, and ICF International; 2015.

\section{Publisher's Note}

Springer Nature remains neutral with regard to jurisdictional claims in published maps and institutional affiliations.

Ready to submit your research? Choose BMC and benefit from:

- fast, convenient online submission

- thorough peer review by experienced researchers in your field

- rapid publication on acceptance

- support for research data, including large and complex data types

- gold Open Access which fosters wider collaboration and increased citations

- maximum visibility for your research: over $100 \mathrm{M}$ website views per year

At $\mathrm{BMC}$, research is always in progress.

Learn more biomedcentral.com/submissions 